\title{
Anorexia nervosa and bone
}

\author{
Madhusmita Misra ${ }^{1,2}$ and Anne Klibanski ${ }^{1}$ \\ ${ }^{1}$ BUL 457, Neuroendocrine Unit, Massachusetts General Hospital and Harvard Medical School, \\ 55 Fruit Street, Boston, Massachusetts 02114, USA \\ ${ }^{2}$ Pediatric Endocrine Unit, Massachusetts General Hospital for Children and Harvard Medical School, \\ Boston, Massachusetts 02114, USA
}

Correspondence should be addressed to M Misra

Email

mmisra@partners.org

\begin{abstract}
Anorexia nervosa (AN) is a condition of severe low weight that is associated with low bone mass, impaired bone structure, and reduced bone strength, all of which contribute to increased fracture risk. Adolescents with AN have decreased rates of bone accrual compared with normal-weight controls, raising additional concerns of suboptimal peak bone mass and future bone health in this age group. Changes in lean mass and compartmental fat depots, and hormonal alterations secondary to nutritional factors contribute to impaired bone metabolism in AN. The best strategy to improve bone density is to regain weight and menstrual function. Oral estrogen-progesterone combinations are not effective in increasing bone density in adults or adolescents with AN, and transdermal testosterone replacement is not effective in increasing bone density in adult women with AN. However, physiological estrogen replacement as transdermal estradiol with cyclic progesterone does increase bone accrual rates in adolescents with AN to approximate that in normal-weight controls, leading to a maintenance of bone density Z-scores. A recent study has shown that risedronate increases bone density at the spine and hip in adult women with AN. However, bisphosphonates should be used with great caution in women of reproductive age, given their long half-life and potential for teratogenicity, and should be considered only in patients with low bone density and clinically significant fractures when non-pharmacological therapies for weight gain are ineffective. Further studies are necessary to determine the best therapeutic strategies for low bone density in AN.
\end{abstract}

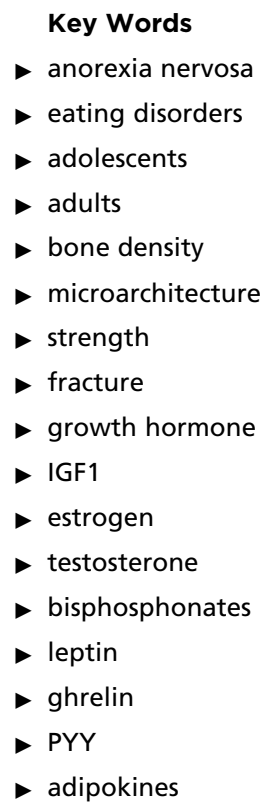

Journal of Endocrinology (2014) 221, R163-R176

\section{Introduction}

Anorexia nervosa (AN) is a condition of severe low weight associated with impaired body image and an intense fear of gaining weight that is reported in $0.2-1 \%$ of women (Lucas et al. 1991). Although most commonly diagnosed in women, in one study, 5-15\% of all subjects diagnosed with AN were male (Andersen \& Holman 1997). The 2013 DSM V criteria eliminated the requirement of amenorrhea for the diagnosis of AN. With the revised diagnostic criteria, the prevalence of $\mathrm{AN}$ in women is expected to increase to as much as 4\% (Smink et al. 2013). Subtypes of AN include the restrictive and the binge-purge subtypes, both of which are associated with low body weight. Most available data on effects of AN on bone metabolism are based on studies that used DSM IV criteria for diagnosis of $\mathrm{AN}$, and the effect of using the new DSM V criteria remains unknown. This review will discuss the impact of AN on bone density, microarchitecture, and strength estimates, as well as fracture risk. We will also discuss the determinants of impaired bone metabolism in AN and possible therapeutic interventions to optimize bone health in this condition. 


\section{Impact of AN on bone}

Numerous studies have reported the deleterious effects of AN on bone health (Biller et al. 1989a, Bachrach et al. 1990, Grinspoon et al. 2000, Jagielska et al. 2002, Misra et al. $2004 a, c$ ) associated with increased fracture risk (Lucas et al. 1999, Espallargues et al. 2001, Faje et al. 2014). While earlier studies examined the effects of AN on bone density parameters, more recent studies have reported on the effects of this disorder on measures of bone microarchitecture and strength estimates using state-of-the-art methodologies.

\section{Bone mineral density}

Low bone mineral density (BMD) is characteristic of AN and affects both adults (Biller et al. 1989a, Grinspoon et al. 2000) and adolescents (Bachrach et al. 1990, Jagielska et al. 2002, Misra et al. 2004a,c) with this condition. Both trabecular and cortical bone sites are affected in AN, although overall data suggest that sites of trabecular bone (such as the lumbar spine) are affected more severely than sites of predominantly cortical bone (such as the hip and whole body) in females. This has been attributed to the profound estrogen deficiency that typically accompanies this disorder. In community-dwelling adult women with AN, more than $90 \%$ have $T$-scores of $<-1$, and $\sim 40 \%$ have $T$-scores of $<-2.5$ at one or more sites (Grinspoon et al. 2000). Adolescent girls with $\mathrm{AN}$ are also at high risk for low bone density (Fig. 1), and in one study, more than

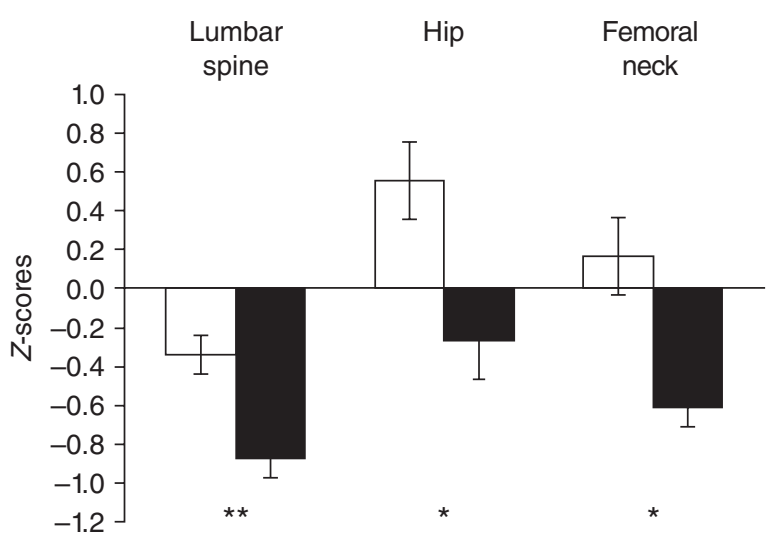

Figure 1

Z-scores for lumbar spine, hip, and femoral neck bone mineral densities (BMDs) in girls with anorexia nervosa (AN) (black bars) and healthy control subjects (white bars). Girls with AN had significantly lower $Z$-scores at each site than healthy adolescents. $* P<0.01$ and $* * P \leq 0.001$. Reproduced with permission from Pediatrics, Vol. 114, Page(s) 1574-1583, Copyright 2004 by the AAP (Misra et al. 2004a).
$50 \%$ had BMD Z-scores of $<-1$ at one or more sites (Misra et al. 2004a,c). In addition to cross-sectional reports of low $\mathrm{BMD}$, adolescents with AN have significant reductions in bone accrual rates over time compared with controls (Soyka et al. 2002, Misra et al. 2008a; Fig. 2). Reduced bone accrual is a major concern during the adolescent years because this is a time when marked increases occur in bone accrual in healthy teenagers toward attainment of peak bone mass (Theintz et al. 1992, Bachrach 2001), an important determinant of future fracture risk. Adolescence thus represents a window in time during which bone accrual needs to be maximized in order to attain an optimal peak bone mass, and deficits incurred during this time may be permanent. In fact, women with $\mathrm{AN}$ who develop AN during the adolescent years tend to have lower bone density than those who develop this condition in adult life, despite a similar duration of amenorrhea (Biller et al. 1989b).

In addition to women, males with $\mathrm{AN}$ are at high risk for low bone density, and we have reported BMD $Z$-scores of $<-1$ at the femoral neck and lumbar spine in 65 and $50 \%$ of boys with AN 12-19 years old, compared with only 18 and $24 \%$ of normal-weight boys in the same age range (Misra et al. 2008b). Therefore, in contrast to women, males with AN have greater involvement of sites of predominantly cortical bone.

Most early studies used dual-energy X-ray absorptiometry (DXA) to measure BMD, and DXA reports 'areal' BMD (aBMD; bone mineral content/cross-sectional area of bone), rather than 'volumetric' BMD (vBMD; bone mineral content/bone volume). aBMD is susceptible to artifactual changes based on body size, such that shorter subjects have lower reported aBMD than taller subjects, even when vBMD is similar. Surrogates for vBMD, such as lumbar bone mineral apparent density (BMAD) are also significantly lower in those with AN than in a normal-weight control population (Misra et al. 2004a,c, 2008a).

Quantitative computed tomography (QCT) is a methodology that allows measurement of vBMD in vivo and remains a research tool in 2014. QCT can measure vBMD at the spine and hip, while peripheral QCT (pQCT) and high-resolution pQCT (HRpQCT) have been used to measure vBMD at the distal radius in both adult women and adolescent girls with this disorder. Adult women with AN have decreases in cortical vBMD (Milos et al. 2005), and we have reported lower total and trabecular vBMD at the distal radius in adolescent girls with AN compared with controls (Faje et al. 2013a) (Fig. 3).

Published by Bioscientifica Ltd 

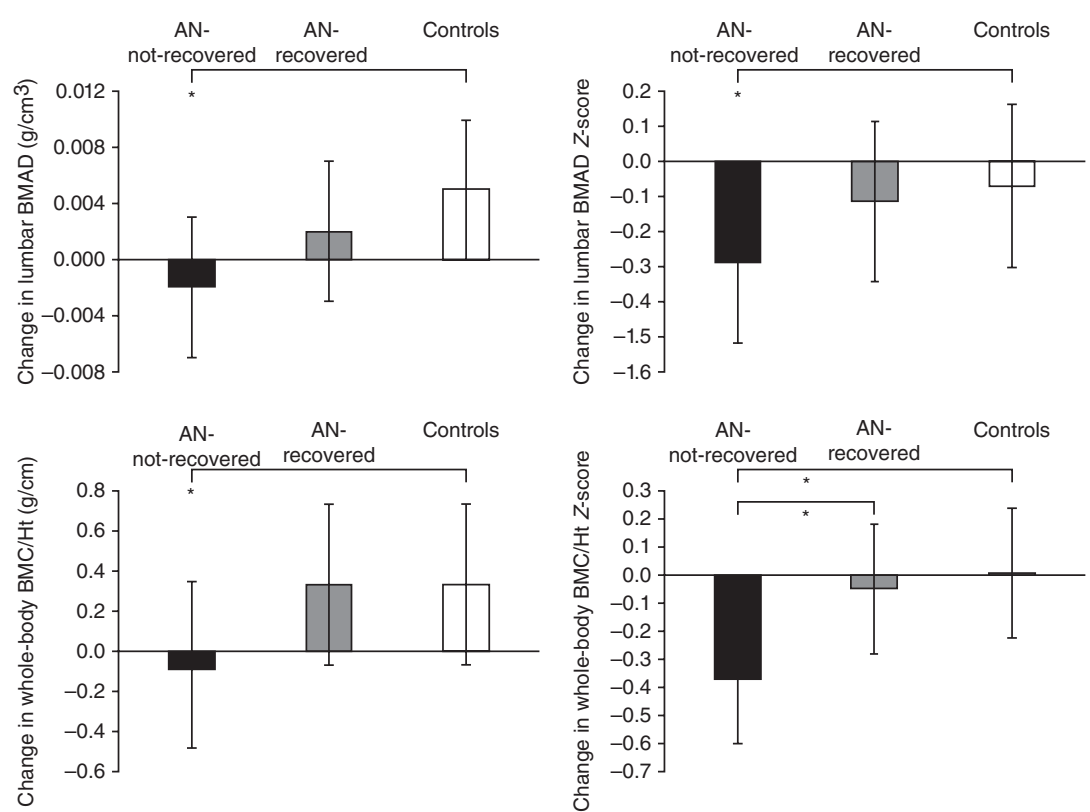

Figure 2

Change in lumbar bone mineral apparent density (BMAD) and whole-body bone mineral content/height (WB BMC/Ht) measures in anorexia nervosa (AN)-not-recovered (black bars), AN-recovered (gray bars), and healthy adolescents (white bars) over 1 year. AN-not-recovered adolescents continued to lose bone mass over the 1-year follow-up period, and the change in bone density measures was significantly lower in this group compared with

\section{Bone geometry and microarchitecture}

Both pQCT and HRpQCT can measure size parameters of bone, and adult and adolescent women with $\mathrm{AN}$ have reductions in cortical thickness and cortical area, with coincident increases in trabecular area (Milos et al. 2005, Lawson et al. 2010, Faje et al. 2013a). This is likely consequent to estrogen deficiency in AN. Estrogen prevents endosteal bone resorption (Riggs et al. 2002), and thus, low estrogen levels would be expected to lead to an increase in endosteal bone resorption and reductions in cortical area, exactly what is observed in AN. As cortical thickness is an important determinant of bone strength (Faje et al. 2013a), reductions in cortical thickness likely contribute to increased fracture risk.

HRpQCT can assess bone microarchitecture, and we have reported that adolescent girls with AN have increased cortical porosity and decreased trabecular thickness compared with normal-weight controls (Faje et al. 2013a). Similarly, adult women with AN have reductions in trabecular number and thickness with increased trabecular separation (Milos et al. 2005, Lawson et al. 2010). Abnormalities in microarchitecture may precede changes observed using DXA scanning. Using flat panel controls (the Tukey-Kramer test was used for multiple comparisons). AN-recovered adolescents did not differ from controls regarding change in bone density parameters and differed significantly from AN-not-recovered adolescents regarding change in whole-body bone density $Z$-scores. ${ }^{*} P<0.05$. Republished with permission of The Endocrine Society, from Misra et al. 2008b; permission conveyed through Copyright Clearance Center, Inc.

ultra-high-resolution volumetric CT, we reported that bone microarchitecture may be affected in adolescent girls with AN even before significant reductions occur in DXA reports of aBMD (Bredella et al. 2008).

Data are currently lacking regarding bone geometry and microarchitecture changes using QCT in males with AN. However, hip structural analysis (HSA, from DXA) is a validated technique to measure bone geometry at the hip and to assess fracture risk (Schousboe et al. 2013). Using HSA, we have reported lower cross-sectional area, cross-sectional moment of inertia, and section modulus in boys with AN at the narrow neck, trochanteric region, and femoral shaft, compared with normal-weight controls after controlling for age and height (Misra et al. 2013). Lower cortical thickness at the narrow neck and trochanteric region, and greater buckling ratio at the trochanteric region were also shown (Misra et al. 2013). These changes suggest reduced bone strength at the hip and femoral neck in males with AN. Future studies using QCT techniques are necessary to confirm these findings.

\section{Bone strength estimates and fracture risk}

Microfinite element analysis ( $\mu \mathrm{FEA}$ ) allows estimation of bone strength using data from HRpQCT and advanced

Published by Bioscientifica Ltd 
$\square$ Controls $\quad$ AN

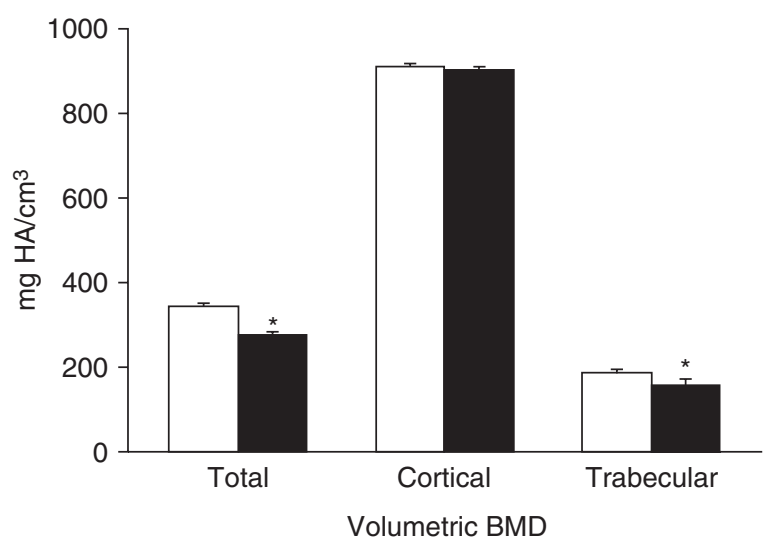

Figure 3

Volumetric bone mineral density (BMD) assessed by HRpQCT in adolescent girls with anorexia nervosa (black bars) and normal-weight controls (white bars). Girls with anorexia nervosa had significantly lower total and trabecular volumetric BMDs than controls. ${ }^{*} P<0.05$. Adapted and republished with permission of The Endocrine Society, from Faje et al. 2013b; permission conveyed through Copyright Clearance Center, Inc.

engineering modeling techniques. Strength estimates (stiffness and failure load) of the distal radius assessed using $\mu \mathrm{FEA}$ are markedly lower in adult and adolescent women with AN compared with normal-weight controls (Milos et al. 2005, Faje et al. 2013a). Consistent with these studies, an increase in fracture risk has been reported in both adults and adolescents with AN (Lucas et al. 1999, Espallargues et al. 2001, Faje et al. 2014). In adolescents, we have reported historical occurrence of one or more fractures in $31 \%$ of girls compared with $19 \%$ of normal-weight healthy controls (Faje et al. 2014). Interestingly, we found that fracture risk was increased in girls with AN compared with controls even at relatively normal BMD $Z$-scores of $<-1$ (and not just $<-2$; Faje et al. 2014), raising concerns that changes in bone geometry and structure occur at relatively 'normal' BMD $Z$-scores in adolescents with AN to increase fracture risk. Consistent with these findings, another study reported that spine aBMD and measures of disease duration and severity did not predict the occurrence of incident vertebral fractures in adolescents and young adults with AN using the Genant semiquantitative technique. Of note, in this study, $12.5 \%$ of the women developed incident vertebral fractures over 18 months of follow-up (Divasta et al. 2014a).

\section{Surrogate markers of bone turnover}

In order to better understand the pathophysiology underlying changes in bone density and structure in $\mathrm{AN}$, it is important to examine surrogate markers of bone turnover. Normal adults and adolescents differ in patterns of biochemical markers of bone turnover and the patterns are different in AN as well. Adult women with AN have a decrease in markers of bone formation (Grinspoon et al. 1996, Hotta et al. 1998) and an increase in markers of bone resorption (Grinspoon et al. 1996, Hotta et al. 1998, Zipfel et al. 2001), consistent with an uncoupling of bone turnover leading to impaired bone metabolism. By contrast, adolescent girls and boys with AN have a 'lowturnover state' with decreases in both bone formation and bone resorption markers (Soyka et al. 2002, Misra et al. 2011), reflective of a coupled decrease in bone turnover. These findings are in contrast to the increased bone turnover state of normal adolescence (Mora et al. 1999).

\section{Effects of weight gain and menstrual recovery on bone parameters}

Recovery from AN is key to improving bone health. In adults with AN, our studies have shown increases in bone density following weight gain and/or menstrual recovery. Weight gain leads to increases in bone density at the total hip, a predominantly cortical site, whereas menstrual recovery leads to increases in bone density at the spine, a predominantly trabecular site (Miller et al. 2006; Fig. 4). Weight gain with menstrual recovery results in a mean annual increase in BMD of $3.1 \%$ at the spine and $1.8 \%$ at the hip (Miller et al. 2006). In adolescents with $\mathrm{AN}$, we have demonstrated a modest improvement in bone accrual rates following weight gain and menstrual recovery, and not to the extent observed in normal-weight healthy controls (Misra et al. 2008a). However, this is an improvement to the reductions in bone density observed over time in those who do not gain weight and/or recover menses (Misra et al. 2008a; Fig. 2). Thus, while bone density $Z$-scores continue to decrease in non-recovered adolescents, the decrease in $Z$-scores is attenuated in those who gain weight and resume menses. We have also shown that biochemical markers of bone turnover increase with weight gain in adolescents with $\mathrm{AN}$, and an improvement in bone turnover markers over the initial 6 months predicts increases in bone mineral content in the subsequent 6 months (Soyka et al. 2002). These data suggest that with persistent weight recovery, one is likely to observe a significant improvement in bone parameters. Data are currently lacking regarding the impact of weight gain and/or resumption of menses on bone geometry, microarchitecture and strength estimates, and fracture risk.

Published by Bioscientifica Ltd. 

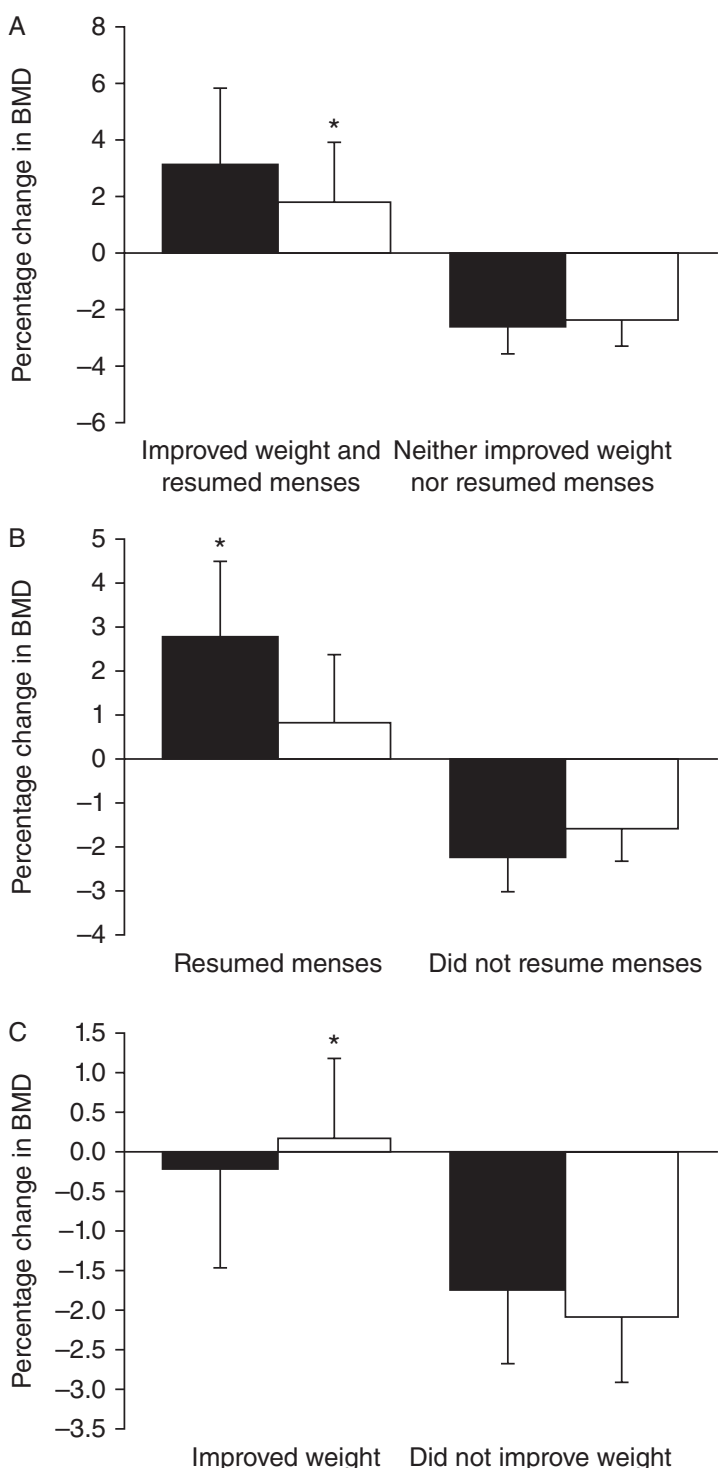

Figure 4

Impact of weight and/or menstrual recovery on bone density parameters in adult women with anorexia nervosa not receiving oral contraceptives. (A) Women who both improved weight and resumed menses had an increased BMD at the PA spine and hip compared with those who neither improved weight nor resumed menses. (B) Women who resumed menses had an increased PA spine BMD (but not hip BMD) compared with those who did not improve menstrual function. (C) Women who improved weight had an increased hip BMD (but not PA spine BMD) compared with those who did not improve weight. Black bars, PA spine BMD and white bars, hip BMD. $* P<0.05$. Republished with permission of The Endocrine Society, from Miller et al. 2006; permission conveyed through Copyright Clearance Center, Inc.

\section{Factors contributing to impaired bone metabolism in AN}

Herein, the body composition, and nutritional and hormonal changes that contribute to poor bone health in $\mathrm{AN}$ are discussed. Knowing the determinants of low bone density and impaired bone structure in $\mathrm{AN}$ is essential to develop the appropriate therapeutic strategies to optimize bone density and structure in adults and adolescents with AN.

\section{Changes in body composition}

AN is characterized by marked reductions in fat mass and less marked but significant reductions in lean mass (Soyka et al. 2002, Misra et al. 2004a,c, Miller et al. 2006, Faje et al. 2013a). Lower lean mass is an important determinant of lower bone density and impaired bone structure in adults and adolescents with AN (Soyka et al. 2002, Misra et al. 2004a,c, Miller et al. 2006, Faje et al. 2013a). We have also shown that increases in lean mass following weight gain are strongly predictive of coincident increases in bone density in adolescents with AN (Soyka et al. 2002). Similar to females, lean mass is an important determinant of bone density in males with AN and of HSA parameters (Misra et al. 2008b, 2013).

Recent studies have examined compartmental fat stores in AN, and our group has reported higher marrow adiposity using magnetic resonance spectroscopy in women with AN compared with normal-weight controls (Fig. 5) and women who have recovered from AN (Bredella et al. 2009, Fazeli et al. 2012). Increased marrow adiposity in AN is associated with lower aBMD (Bredella et al. 2009),

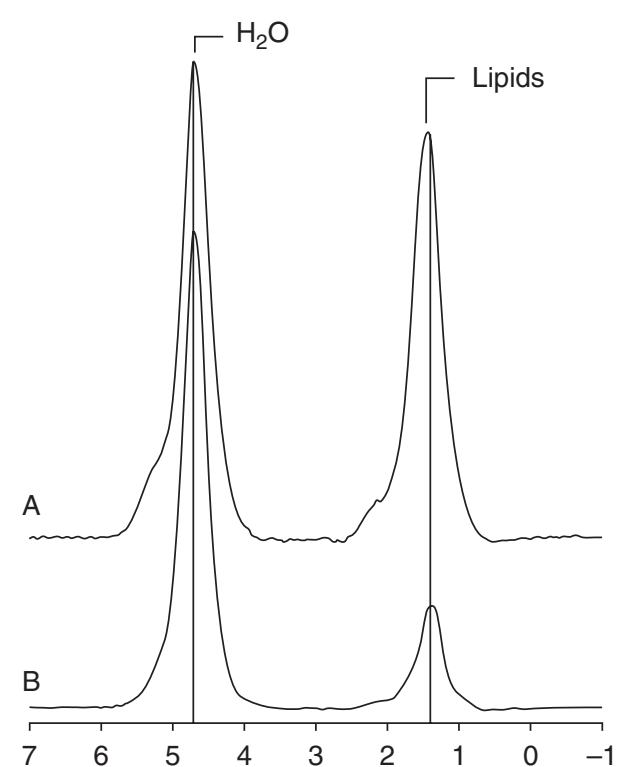

\section{Figure 5}

${ }^{1} \mathrm{H}$-magnetic resonance spectra of L4 marrow obtained at 3.0T from a subject with anorexia nervosa (A) and an age-matched healthy control (B). The prominent lipid resonance in $(A)$ indicates a relatively higher marrow fat content. Republished with permission of The Endocrine Society, from Bredella et al. 2009; permission conveyed through Copyright Clearance Center, Inc.

Published by Bioscientifica Ltd. 
consistent with the reports of a reciprocal relationship between marrow fat and bone in studies of healthy children and adults (Lewiecki et al. 2008). Preadipocyte factor 1 (PREF1, now known as DLK1) is a member of the epidermal growth factor-like family of proteins, which inhibits differentiation of the mesenchymal progenitor stem cell along the osteoblast pathway, and women with AN have higher PREF1 levels than controls and recovered women (Fazeli et al. 2010a, 2012). Higher PREF1 levels in AN are associated inversely with aBMD and positively with marrow fat (Fazeli et al. 2010a). Increased marrow adiposity is considered to reduce the biomechanical strength of bone (compared with hemopoietic marrow; Schellinger et al. 2001) and may contribute to increased fracture risk in AN.

Cold-induced brown adipose tissue (BAT) activity can now be assessed using PET-CT and PET-MRI scans, and young women with AN are less likely to have cold-induced BAT activity than controls (Bredella et al. 2012). As BAT increases energy expenditure and shivering thermogenesis, reductions in BAT activity likely represent an adaptive mechanism to conserve energy in AN, a state of very-lowenergy stores (as indicated by marked reductions in body fat mass). Of importance, BAT activity has also been demonstrated to be bone anabolic (Ponrartana et al. 2012, Lee et al. 2013), thus reductions in BAT activity in women with AN may contribute to lower BMD. In fact, positive associations of lower BAT activity and lower BMD are reported in women with AN (Bredella et al. 2012).

\section{Exercise activity}

There are limited data regarding the impact of exercise activity on bone metabolism in AN. Although mechanical loading is known to be beneficial to bone health, because exercise typically leads to increases in energy expenditure, management of AN includes limiting exercise activity to conserve energy stores.

\section{Calcium and vitamin D status}

Although it is clear that optimizing calcium and vitamin D status is essential to optimize bone mineralization, most adults and adolescents with AN have a higher calcium and vitamin $\mathrm{D}$ intake than a control population due to an increased use of supplements (Hadigan et al. 2000, Misra et al. 2006a). In adolescents with AN, we have shown that vitamin $\mathrm{D}$ intake is lower than the recommended daily allowance (RDA) in only $23 \%$ of girls with AN compared with $50 \%$ of controls, and calcium intake is lower than the RDA in $41 \%$ of girls with AN compared with $70 \%$ of controls
(Misra et al. 2006a). Consistent with an increased supplement intake, 25-hydroxy vitamin D levels are higher in those with AN than in controls (Misra et al. 2011). One study has reported that a daily calcium intake of $<600 \mathrm{mg}$ is associated with lower bone density (Castro et al. 2000). However, most studies have failed to demonstrate a relationship between calcium or vitamin $\mathrm{D}$ intake and bone parameters in $\mathrm{AN}$.

\section{Changes in hormonal axes}

AN is associated with marked changes in almost every endocrine axis, and most of these are adaptive changes that help conserve energy for vital functions, stimulate food intake, or maintain euglycemia. However, many of these hormonal changes have potential deleterious effects on bone. This section will discuss the impact of known hormonal changes in AN on bone.

Hypothalamic-pituitary-gonadal axis Although amenorrhea is no longer required for the diagnosis of AN as per the DSM V criteria, hypothalamic amenorrhea is a common finding in women with AN. Suppression of the hypothalamic-pituitary-gonadal axis is advantageous in a state of very low energy availability, as reproduction would divert available energy from that required for maintenance of vital body functions. In adolescents with AN, menarche may be delayed, and menarcheal delay is an important determinant of low bone density (Misra et al. 2004a,c).

The gonadal steroids, both estrogen and testosterone, are critical for bone accrual during adolescence and for maintaining bone density in adults. Estrogen inhibits osteoclastic bone resorption (Riggs 2000) and also inhibits sclerostin and PREF1 (Modder et al. 2011, Faje et al. 2013b, Divasta et al. 2014a), effects that should lead to an increase in bone density. Sclerostin is a product of osteocytes, which inhibits WNT signaling and thus osteoblastic activity (Modder et al. 2011). PREF1, as previously discussed, decreases differentiation of the mesenchymal progenitor stem cell along the osteoblast pathway (Wang \& Sul 2009). Testosterone acts primarily to prevent osteoclastic bone resorption following its aromatization to estrogen and also has proposed direct bone anabolic effects (Riggs et al. 2002). During adolescence, rising estradiol $\left(\mathrm{E}_{2}\right)$ levels in girls and aromatization of testosterone to $\mathrm{E}_{2}$ in boys inhibit endosteal bone resorption leading to increased cortical thickness, while rising testosterone levels in boys (along with rising levels of growth hormone (GH) and insulin-like growth factor 1 (IGF1)) contribute to periosteal bone apposition. In women and adolescent girls with $\mathrm{AN}$, lower $\mathrm{E}_{2}$ levels and duration of amenorrhea (Biller et al. 1989a,

Published by Bioscientifica Ltd. 
Bachrach et al. 1990, Baker et al. 2000, Castro et al. 2000, Misra et al. 2004a,c) are key determinants of low bone density. In boys with AN, low testosterone levels predict low spine BMD whereas low BMI and lean mass predict lower total hip and femoral neck BMDs (Misra et al. 2008b).

GH-IGF1 axis Puberty is characterized by increases in GH and IGF1, both of which are bone anabolic and facilitate periosteal bone apposition. By contrast, AN is associated with marked reductions in IGF1 levels in both adolescents and adults, and low IGF1 levels correlate with lower levels of bone formation markers and lower BMD (Grinspoon et al. 2002, Soyka et al. 2002, Misra et al. 2003a). Furthermore, IGF1 levels correlate positively with measures of bone microarchitecture (Lawson et al. 2010, Faje et al. 2013a). Despite low IGF1 levels, GH concentrations are increased in AN, indicative of a nutritionally acquired hepatic GH resistance (Argente et al. 1997, Scacchi et al. 1997, Stoving et al. 1999, Misra et al. 2003a). While GH concentrations are strongly associated with concentrations of biochemical markers of bone turnover in normal-weight adolescents, these associations are lost in girls with AN, suggesting GH resistance in bone (in addition to the liver; Misra et al. 2003a). Furthermore, administration of supraphysiological doses of recombinant human GH (rhGH) to adult women with AN fails to increase IGF1 levels or levels of bone turnover markers (Fazeli et al. 2010b), further corroborating the concept of GH resistance.

Hypothalamic-pituitary-adrenal axis Both adults and adolescents with AN have higher serum and urinary cortisol levels compared with normal-weight controls (Misra et al. 2004b, Lawson et al. 2009). This state of relative hypercortisolemia may be an adaptive mechanism in AN, as cortisol is a gluconeogenic hormone. However, hypercortisolemia has multiple deleterious effects on bone, and girls and women with AN and higher cortisol levels have lower measures of bone formation markers and lower BMD (Misra et al. 2004b, Lawson et al. 2009).

Adipokines Leptin is an adipokine that is anorexigenic and has effects on bone. While central leptin is deleterious to the axial skeleton (Ducy et al. 2000, Hamrick et al. 2004), peripheral leptin has bone anabolic effects (with possible osteoclast inhibitory effects as well), particularly on the appendicular skeleton (Hamrick et al. 2004, Hamrick et al. 2005). Levels of leptin are low in AN (Mehler et al. 1999, Misra et al. 2005a), probably an adaptive mechanism to increase appetite, and lower leptin levels are associated with lower fat mass and bone density measures
(Lawson et al. 2010). Adiponectin is another adipokine that is deleterious to bone based on studies in post-menopausal women and adult men (Jurimae et al. 2008, Biver et al. 2011). Levels of adiponectin have been variably reported to be high, normal, or low in adults and adolescents with AN (Tagami et al. 2004, Housova et al. 2005, Misra et al. 2007, Amitani et al. 2013). At least one study reported that all adiponectin isoforms should be evaluated in AN (in addition to total adiponectin) and that percent highmolecular-weight adiponectin correlates positively with BMI (Amitani et al. 2013). We have reported that higher adiponectin levels corrected for fat mass in girls with AN predict lower spine BMD and BMAD (Misra et al. 2007).

Enteric hormones Insulin and amylin are bone anabolic, and levels of both hormones are reduced in AN and are associated with lower levels of bone formation markers and lower BMD (Misra et al. 2007, Wojcik et al. 2010). Ghrelin is an orexigenic hormone and GH secretagogue, secreted by the gastric fundus (Kojima et al. 1999). Ghrelin increases osteoblastic activity in cell cultures, suggestive of bone anabolic effects (Kim et al. 2005). Levels of ghrelin are increased in AN compared with normal-weight controls (Misra et al. 2004a,c, 2005b, Lawson et al. 2011a), probably an adaptive change to increase appetite and thus caloric intake. Although ghrelin levels positively predict bone density in healthy subjects, we found no associations of ghrelin levels with bone measures in girls with AN, probably representing a state of ghrelin resistance in AN (Misra et al. 2005b). Finally, peptide YY (PYY) is an enteric anorexigenic hormone secreted by the endocrine L-cells of the distal gut (Batterham et al. 2002) that inhibits osteoblast activity and is thus deleterious to bone (Wong et al. 2012). PYY levels are paradoxically higher in girls with AN than controls (Misra et al. 2006b), and therefore, may not be adaptive to the low-energy state. In addition, in contrast to many endocrine abnormalities that reverse with weight gain, PYY levels may be persistently abnormal even with weight recovery. Higher PYY levels are an independent predictor of lower levels of bone turnover markers in adolescents and lower bone density measures in adults with AN (Misra et al. 2006b, Utz et al. 2008).

Other hormones Oxytocin is now known to have anorexigenic and bone anabolic effects (Tamma et al. 2009), and oxytocin levels are lower in women with AN than controls and are associated with lower BMD (Lawson et al. 2011b). Fig. 6 summarizes the various hormonal contributions to low bone density in AN.

Published by Bioscientifica Ltd. 


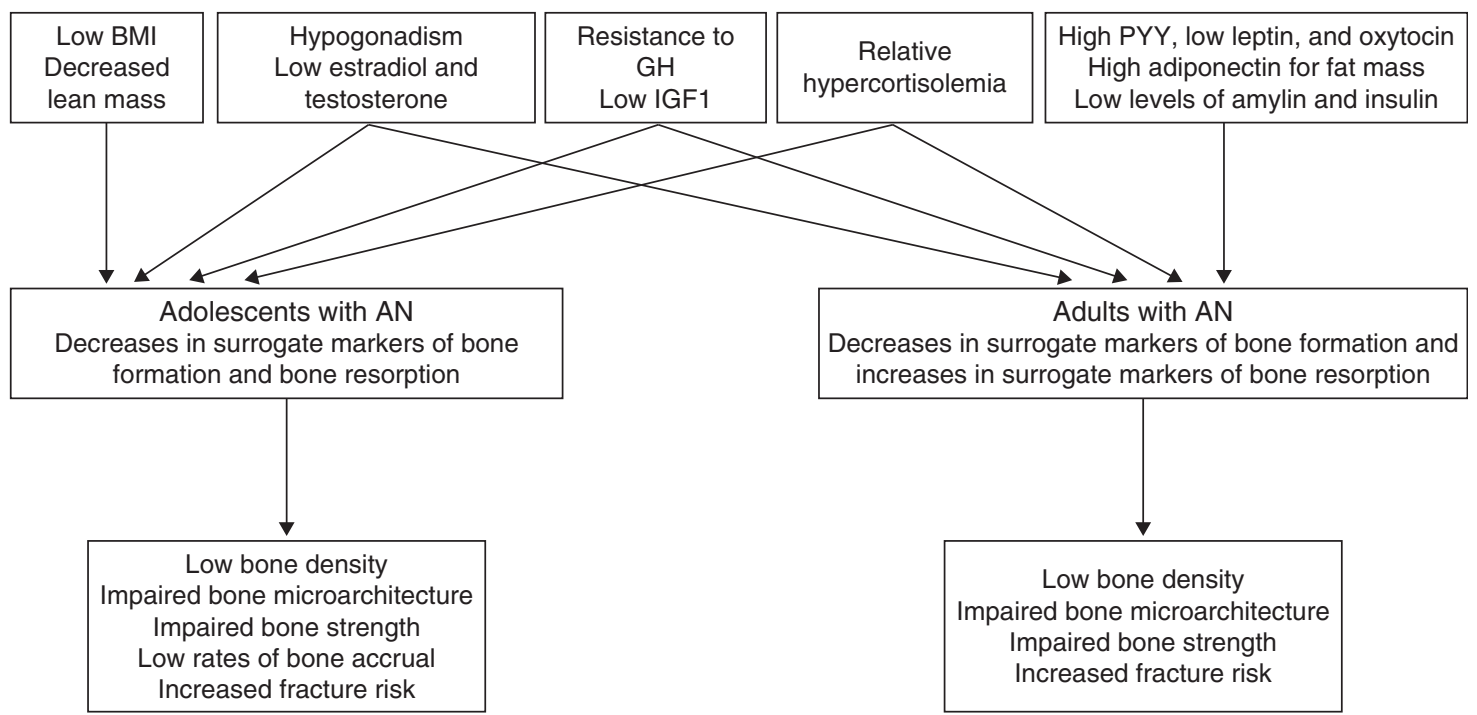

Figure 6

Pathophysiology contributing to impaired bone metabolism in adolescents and adults with anorexia nervosa. Adapted and reproduced with permission from Misra M \& Klibanski A, Current Opinion in Endocrinology,

\section{Treatment strategies to optimize bone density in adults and bone accrual in adolescents}

All subjects with AN should be assessed for bone density by DXA at diagnosis and at periodic intervals thereafter depending on disease course. However, DXA results should be adjusted for body size and interpreted carefully based on the guidelines from the International Society of Clinical Densitometry (Lewiecki et al. 2008, Schousboe et al. 2013). The future role of clinical assessment of bone microarchitecture and strength remains to be determined, but is likely important based on the poor correlation of aBMD measures with fractures. Management strategies include behavioral modifications, hormone replacement, and pharmacological therapy.

\section{Weight gain and restoration of menstrual function}

The most important and most effective strategy to improve bone density in $\mathrm{AN}$ is normalization of weight and restoration of menstrual function. We have reported increases in spine and hip BMDs by 3.1 and 1.8\% following weight gain and menstrual recovery in adult women with AN (Miller et al. 2006). Adolescents with AN also have an improvement in bone density measures following weight gain and menses restoration, although complete catch-up does not occur (Misra et al. 2008a). This may be because of intermittent relapses or because of persistence of
Diabetes, and Obesity 2011 18(6) 376-382. Copyright 2011 Wolters Kluwer Health, Lippincott Williams \& Wilkins.

certain hormonal alterations (such as hypercortisolemia (Misra et al. 2004b)) that are deleterious to bone.

\section{Calcium and vitamin D supplementation}

As calcium and vitamin D intake is typically higher in girls and women with AN than in controls (Hadigan et al. 2000, Misra et al. 2006a), calcium and vitamin D supplementation alone is not effective in increasing bone density in this condition (Klibanski et al. 1995, Soyka et al. 2002). However, given the known beneficial effects of calcium and vitamin $\mathrm{D}$ (which increases gut absorption of calcium) on bone mineralization, it is important to optimize the intake of these micronutrients in $\mathrm{AN}$ if suboptimal.

\section{Hormonal strategies}

An important consideration in managing low bone density in $\mathrm{AN}$ is the replacement of hormones that are low in AN, such as the gonadal steroids and IGF1. Other hormones that are low in AN and contribute to low BMD include insulin, leptin, amylin, and oxytocin. However, replacement of these hormones is not currently indicated because of associated deleterious effects, such as hypoglycemia with amylin, and because of the anorexigenic effects of leptin. Increases in cortisol, adiponectin, and PYY are also challenging to address. Medications that reduce cortisol levels are associated with various adverse

Published by Bioscientifica Ltd. 
effects including the risk of hypocortisolemia, and there are currently no PYY or adiponectin antagonists available for use in humans.

Gonadal steroid replacement Several studies have examined the effects of estrogen replacement on bone density in adults and adolescents with AN. Most studies have demonstrated that oral estrogen replacement as the estrogen-progesterone combination pill is not effective in increasing bone density in adults or adolescents with AN (Klibanski et al. 1995, Golden et al. 2002, Strokosch et al. 2006). This has variably been attributed to the IGF1 suppressive effects of oral estrogen from its hepatic first pass effects, and to the dose and type of estrogen used. By contrast, we have demonstrated in an 18-month randomized controlled trial (RCT) that physiological estrogen replacement as transdermal $17 \beta-E_{2}$, which is not IGF1 suppressive, with cyclic progesterone, increases bone accrual rates at the spine and hip in adolescents with AN to approximate rates in normal-weight controls, even after controlling for age and weight changes over time (Misra et al. 2011) (Fig. 7). This results in the maintenance of BMD $Z$-scores in girls with $\mathrm{AN}$, whereas there is a decrease in BMD $Z$-scores over time in girls with AN randomized to placebo. However, physiological estrogen replacement does not lead to an increase in BMD Z-scores; thus, 'catch-up' does not occur, likely because other hormonal alterations persist.

Women with AN are also deficient in testosterone, and in adolescent girls with $\mathrm{AN}$, we have shown that increases

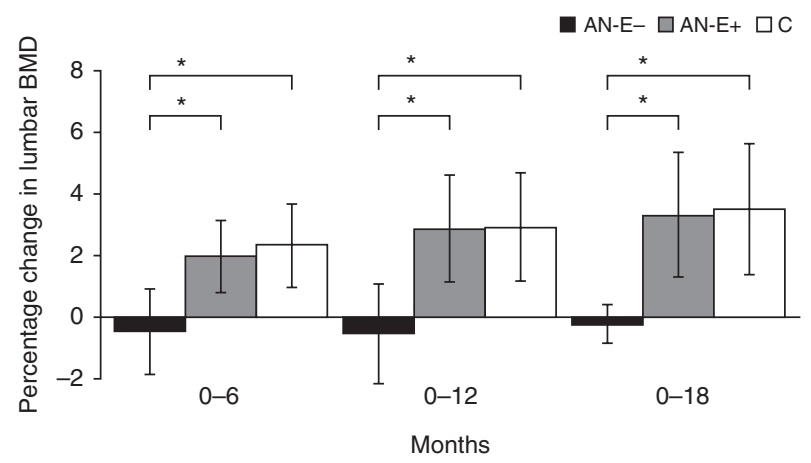

Figure 7

Impact of physiological estrogen replacement on bone density in adolescent girls with anorexia nervosa (AN). Girls with AN randomized to physiological estrogen administration (AN-E + ) had significant increases in bone density at the lumbar spine over 6,12 , and 18 months compared with those randomized to placebo (AN-E-), to approximate bone accrual rates observed in controls (C) (adjusted for baseline age and weight). ${ }^{*} P<0.05$. Reproduced from Misra et al. (2011) by permission of John Wiley \& Sons. Copyright 2011 The American Society for Bone and Mineral Research. in testosterone levels following weight gain are predictive of increases in bone density (Soyka et al. 2002). However, testosterone replacement using the lowdose patch to attain testosterone levels in the upper half of the normal range was not effective in increasing bone density over a 1-year period in adults with AN, despite increases in lean mass and an initial increase in bone formation markers (Miller et al. 2011).

Finally, some (Gordon et al. 1999), though not all (Soyka et al. 2002), studies have reported low levels of the adrenal hormones, DHEA/S, in women with AN, and one study reported maintenance of BMD Z-scores (Divasta et al. 2012) and an improvement in femoral cross-sectional area, section modulus, and cortical thickness (by HSA) (DiVasta et al. 2014b) using a combination of oral estrogen-progesterone (anti-resorptive) and DHEA (weakly bone anabolic) for 18 months in young women with AN.

Low testosterone levels are an important determinant of low bone density in young men and boys with AN (Misra et al. 2008b), suggesting a role for testosterone replacement in males with this disorder. However, data are lacking regarding the effects of testosterone replacement on bone in males with AN.

\section{Supraphysiological doses of rhGH or IGF1} replacement Women and girls with $\mathrm{AN}$ are in a state of GH resistance with high concentrations of GH, but low levels of IGF1 (Argente et al. 1997, Scacchi et al. 1997, Stoving et al. 1999, Misra et al. 2003a). We performed an RCT to determine whether administration of supraphysiological doses of rhGH vs placebo to adult women with AN would be effective in overcoming the state of $\mathrm{GH}$ resistance and lead to an increase in IGF1 levels and bone formation markers (Fazeli et al. 2010b). We found that supraphysiological doses of rhGH were not effective in increasing IGF1 levels or levels of bone turnover markers in adult women with AN. Conversely, these high GH doses led to a further reduction in fat mass, likely consequent to the direct lipolytic effects of GH. A better strategy to address the GH-resistant state in $\mathrm{AN}$ is to administer rhIGF1 to normalize IGF1 levels. Utilizing this strategy, we have demonstrated that rhIGF1 replacement in the short term leads to an increase in bone formation markers in adults and adolescents with AN (Grinspoon et al. 1996, Misra et al. 2009), and when given for 9 months with oral estrogen-progesterone combinations, is effective in increasing bone density significantly in adult women with AN compared with double placebo (Grinspoon et al. 2002) (Fig. 8). We are currently conducting an RCT to

Published by Bioscientifica Ltd 


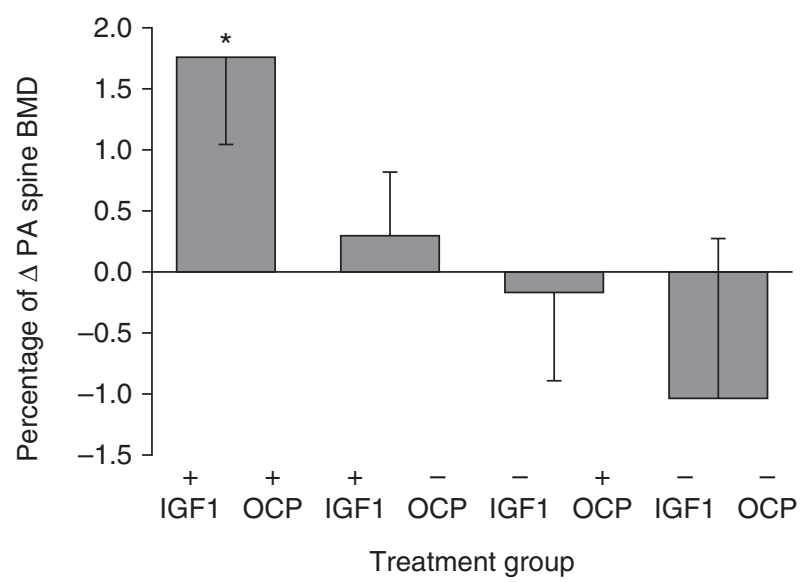

Figure 8

Effect of rhIGF1+/-OCP on BMD. Administration of recombinant human insulin-like growth factor 1 (IGF1; $30 \mu \mathrm{g} / \mathrm{kg}$ b.i.d. subcutaneously) increased bone density in adult women with anorexia nervosa. The effect was most marked when IGF1 was given with a birth control pill. ${ }^{*} P<0.05$. Republished with permission of The Endocrine Society, from Grinspoon et al. 2002; permission conveyed through Copyright Clearance Center, Inc.

determine whether addition of rhIGF1 to transdermal $\mathrm{E}_{2}$ replacement (vs transdermal $\mathrm{E}_{2}$ alone) is effective in increasing BMD $Z$-scores in adolescent girls with $\mathrm{AN}$, and whether this will enable them to 'catch-up' such that their BMD Z-scores approximate that in normal-weight healthy controls.

Recombinant human leptin As subjects with $\mathrm{AN}$ are leptin deficient and leptin has bone anabolic effects, a potential strategy to improve bone density in $\mathrm{AN}$ is to administer rh-leptin. This strategy is intriguing because metreleptin administration has been demonstrated to also restore menses in 60-70\% of normal-weight women with hypothalamic amenorrhea because of its effects on kisspeptin neurons and therefore GnRH pulsatility (Welt et al. 2004, Sienkiewicz et al. 2011). In fact, a study has examined the effects of metreleptin administration on bone in a 9-month RCT in adult women with hypothalamic amenorrhea and reported a significant increase in bone mineral content (but not BMD) with metreleptin (Sienkiewicz et al. 2011). However, leptin administration leads to reductions in appetite and significant reductions in body weight and fat mass (Welt et al. 2004, Sienkiewicz et al. 2011), which would be of major concern in AN.

\section{Other therapeutic options for treating low bone density}

Other options to treat low bone density in AN include pharmacological therapies such as bisphosphonates, teriparatide, and denosumab.
Bisphosphonates These drugs inhibit osteoclastic bone resorption, and we have reported a significant increase in $\mathrm{BMD}$ in adult women with $\mathrm{AN}$ with risedronate compared with placebo in a 1-year RCT (Miller ;et al. 2011; Fig. 9). In this study, spine and hip BMDs increased by 3 and $2 \%$ in women with AN following use of risedronate. However, in adolescents with AN, a 1-year RCT of alendronate vs placebo reported no improvement in spine BMD with alendronate (Golden et al. 2005). These differing results in adults vs adolescents with AN may reflect differences in bone turnover in the two age groups. While bone resorption is increased in adult women with AN (Grinspoon et al. 1996, Hotta etal. 1998, Zipfel etal. 2001), which would suggest that anti-resorptive therapies such as bisphosphonates may be effective in improving bone density, it is decreased in adolescents with AN with an overall reduction in bone turnover (Misra et al. 2003b, 2011). Thus, further reductions in bone turnover with bisphosphonates may not be as effective in improving bone density in an adolescent population. Bisphosphonates also have an extraordinarily long half-life, which has raised concerns regarding their use in adolescents and young women of reproductive age. At this time, bisphosphonate use should be limited to women with osteoporosis who are having fractures and should not be used for low bone density alone.

Teriparatide Teriparatide is known to be effective in increasing bone density in post-menopausal women, and we have reported an increase in spine BMD following 6 months of teriparatide vs placebo in an RCT in older

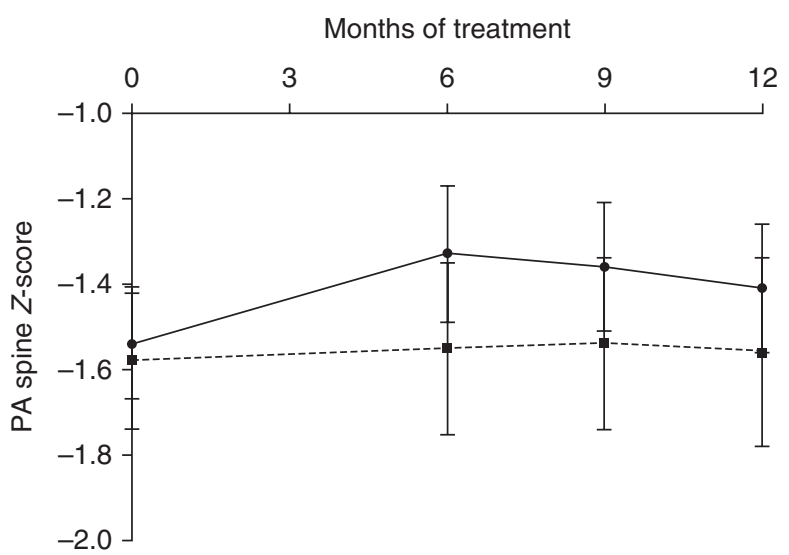

Figure 9

PA spine BMD increased in women receiving risedronate (solid line) over a 12-month period compared with those receiving placebo (dotted line) $(P<0.0001)$. Z-scores are shown. Republished with permission of The Endocrine Society, from Miller et al. 2011; permission conveyed through Copyright Clearance Center, Inc.

Published by Bioscientifica Ltd 
adult women with AN (Fazeli et al. 2014). This was the first study to show the effectiveness of teriparatide in this population and after only 6 months it had an effect much greater than all prior therapies used to increase bone mass in this population. Teriparatide, however, has a black box warning related to reports of osteosarcoma in animal studies and should not be used in those with an increased baseline risk of osteosarcoma, such as children with open epiphyses, subjects with unexplained elevations of ALP, Paget's disease, and a prior history of external beam radiation therapy or implant radiotherapy of the skeleton (product information: Forteo (2004), Eli Lilly and Company, Indianapolis, IN, USA).

Denosumab Denosumab is effective in treating postmenopausal osteoporosis (Diab \& Watts 2013, 2014). However, at this time, no data are available regarding use of denosumab in AN.

\section{General guidelines for treating low bone density in AN}

All subjects with AN should have a structured treatment team that includes (at the very least) a therapist, a nutritionist, and a physician who is an eating disorder specialist. Every effort should be made to optimize caloric intake and thus induce weight gain and restoration of menses. Family-based therapies and cognitive behavioral therapy should be implemented as necessary.

In addition, all subjects with AN should be supplemented with calcium and vitamin D such that they meet the RDA for these micronutrients (1300 mg elemental calcium and $600 \mathrm{IU}$ vitamin D). While it is important to optimize calcium and vitamin D intake, patients should be cautioned that supplementation alone will not be effective in increasing bone density in this condition.

Pharmacological therapy may be considered in women with AN with low bone density and a clinically significant fracture history (as per the ISCD guidelines; Lewiecki et al. 2008), if weight gain strategies are not effective despite best efforts. In addition, hormone replacement therapy using transdermal $17 \beta-\mathrm{E}_{2}(100 \mu \mathrm{g}$ daily) with cyclic progesterone (micronized progesterone, 100-200 mg daily for 12 days of every month) (Misra et al. 2011) may be considered in adolescents with AN whose bone density $Z$-scores are low and are decreasing over time despite all efforts at weight gain, given that the adolescent years are a very narrow window in time during which to optimize bone accrual, and deficits incurred at this time may be permanent.

\section{Conclusion}

Low bone density is an important consequence of AN in adults and adolescents and affects both sexes. Important causes of low bone density include body composition changes and hormonal alterations. The most important strategy to improve bone density in AN is weight gain and menstrual recovery. However, this can be difficult to attain in some women, leading to persistent reductions in bone density over time. Physiological estrogen replacement (with cyclic progesterone) has been demonstrated to be effective in increasing bone accrual rates in adolescents with $\mathrm{AN}$ and to maintain bone density $Z$-scores, although 'catch-up' does not occur. Bisphosphonates are effective in increasing bone density in adult women with AN, but must be used with caution in women of reproductive age, given their very long half-life and potential for teratogenicity. These medications should be reserved for women with low bone density and a clinically significant fracture history when weight gain strategies are ineffective despite best efforts. Studies are ongoing to determine the impact of other therapeutic strategies to improve bone density in adults and adolescents with AN.

Declaration of interest

The authors declare that there is no conflict of interest that could be perceived as prejudicing the impartiality of the research reported.

\section{Funding}

This work was supported in part by NIH grants 1 R01 HD060827, 5 UL1 RR025758, K24HD071843, and 2 R01 DK062249.

\section{References}

Amitani H, Asakawa A, Ogiso K, Nakahara T, Ushikai M, Haruta I, Koyama K, Amitani M, Cheng KC \& Inui A 2013 The role of adiponectin multimers in anorexia nervosa. Nutrition 29 203-206. (doi:10.1016/ j.nut.2012.07.011)

Andersen AE \& Holman JE 1997 Males with eating disorders: challenges for treatment and research. Psychopharmacology Bulletin 33 391-397.

Argente J, Caballo N, Barrios V, Munoz MT, Pozo J, Chowen JA, Morande G \& Hernandez M 1997 Multiple endocrine abnormalities of the growth hormone and insulin-like growth factor axis in patients with anorexia nervosa: effect of short- and long-term weight recuperation. Journal of Clinical Endocrinology and Metabolism 82 2084-2092.

Bachrach L 2001 Acquisition of optimal bone mass in childhood and adolescence. Trends in Endocrinology and Metabolism 12 22-28. (doi:10.1016/S1043-2760(00)00336-2)

Bachrach LK, Guido D, Katzman D, Litt IF \& Marcus R 1990 Decreased bone density in adolescent girls with anorexia nervosa. Pediatrics 86 440-447.

Baker D, Roberts R \& Towell T 2000 Factors predictive of bone mineral density in eating-disordered women: a longitudinal study. International Journal of Eating Disorders 27 29-35. (doi:10.1002/(SICI)1098108X(200001)27:1\%3C;29::AID-EAT3\%3E;3.0.CO;2-P)

Published by Bioscientifica Ltd 
Batterham RL, Cowley MA, Small CJ, Herzog H, Cohen MA, Dakin CL, Wren AM, Brynes AE, Low MJ, Ghatei MA et al. 2002 Gut hormone PYY(3-36) physiologically inhibits food intake. Nature 418 650-654. (doi:10.1038/nature00887)

Biller B, Saxe V, Herzog D, Rosenthal D, Holzman S \& Klibanski A 1989a Mechanisms of osteoporosis in adult and adolescent women with anorexia nervosa. Journal of Clinical Endocrinology and Metabolism 68 548-554. (doi:10.1210/jcem-68-3-548)

Biller BM, Saxe V, Herzog DB, Rosenthal DI, Holzman S \& Klibanski A $1989 b$ Mechanisms of osteoporosis in adult and adolescent women with anorexia nervosa. Journal of Clinical Endocrinology and Metabolism 68 548-554. (doi:10.1210/jcem-68-3-548)

Biver E, Salliot C, Combescure C, Gossec L, Hardouin P, Legroux-Gerot I \& Cortet B 2011 Influence of adipokines and ghrelin on bone mineral density and fracture risk: a systematic review and meta-analysis. Journal of Clinical Endocrinology and Metabolism 96 2703-2713. (doi:10.1210/jc.2011-0047)

Bredella MA, Misra M, Miller KK, Madisch I, Sarwar A, Cheung A, Klibanski A \& Gupta R 2008 Distal radius in adolescent girls with anorexia nervosa: trabecular structure analysis with high-resolution flat-panel volume CT. Radiology 249 938-946. (doi:10.1148/radiol.2492080173)

Bredella MA, Fazeli PK, Miller KK, Misra M, Torriani M, Thomas BJ, Ghomi RH, Rosen CJ \& Klibanski A 2009 Increased bone marrow fat in anorexia nervosa. Journal of Clinical Endocrinology and Metabolism 94 2129-2136. (doi:10.1210/jc.2008-2532)

Bredella MA, Fazeli PK, Freedman LM, Calder G, Lee H, Rosen CJ \& Klibanski A 2012 Young women with cold-activated brown adipose tissue have higher bone mineral density and lower Pref- 1 than women without brown adipose tissue: a study in women with anorexia nervosa, women recovered from anorexia nervosa, and normal-weight women. Journal of Clinical Endocrinology and Metabolism 97 E584-E590. (doi:10.1210/jc.2011-2246)

Castro J, Lazaro L, Pons F, Halperin I \& Toro J 2000 Predictors of bone mineral density reduction in adolescents with anorexia nervosa. Journal of the American Academy of Child and Adolescent Psychiatry 39 1365-1370. (doi:10.1097/00004583-200011000-00010)

Diab DL \& Watts NB 2013 Postmenopausal osteoporosis. Current Opinion in Endocrinology, Diabetes, and Obesity 20 501-509. (doi:10.1097/ 01.med.0000436194.10599.94)

Diab DL \& Watts NB 2014 Denosumab in osteoporosis. Expert Opinion on Drug Safety 13 247-253. (doi:10.1517/14740338.2014.860133)

Divasta AD, Feldman HA, Giancaterino C, Rosen CJ, Leboff MS \& Gordon CM 2012 The effect of gonadal and adrenal steroid therapy on skeletal health in adolescents and young women with anorexia nervosa. Metabolism: Clinical and Experimental 61 1010-1020. (doi:10.1016/j.metabol.2011.11.016)

Divasta AD, Feldman HA \& Gordon CM 2014a Vertebral fracture assessment in adolescents and young women with anorexia nervosa: a case series. Journal of Clinical Densitometry 17 207-211. (doi:10.1016/ j.jocd.2013.02.011)

DiVasta AD, Feldman HA, Beck TJ, LeBoff MS \& Gordon CM $2014 b$ Does hormone replacement normalize bone geometry in adolescents with anorexia nervosa? Journal of Bone and Mineral Research 29 151-157. (doi:10.1002/jbmr.2005)

Ducy P, Amling M, Takeda S, Priemel M, Schilling AF, Beil FT, Shen J, Vinson C, Rueger JM \& Karsenty G 2000 Leptin inhibits bone formation through a hypothalamic relay: a central control of bone mass. Cell $\mathbf{1 0 0}$ 197-207. (doi:10.1016/S0092-8674(00)81558-5)

Espallargues M, Sampietro-Colom L, Estrada MD, Sola M, del Rio L, Setoain J \& Granados A 2001 Identifying bone-mass-related risk factors for fracture to guide bone densitometry measurements: a systematic review of the literature. Osteoporosis International 12 811-822. (doi:10.1007/ s001980170031)

Faje AT, Karim L, Taylor A, Lee H, Miller KK, Mendes N, Meenaghan E, Goldstein MA, Bouxsein ML, Misra M et al. 2013a Adolescent girls with anorexia nervosa have impaired cortical and trabecular microarchitecture and lower estimated bone strength at the distal radius. Journal of Clinical Endocrinology and Metabolism 98 1923-1929. (doi:10.1210/jc.2012-4153)

Faje AT, Fazeli PK, Katzman D, Miller KK, Breggia A, Rosen CJ, Mendes N, Misra M \& Klibanski A 2013b Inhibition of Pref-1 (preadipocyte factor 1) by oestradiol in adolescent girls with anorexia nervosa is associated with improvement in lumbar bone mineral density. Clinical Endocrinology 79 326-332. (doi:10.1111/cen.12144)

Faje AT, Fazeli PK, Miller KK, Katzman DK, Ebrahimi S, Lee H, Mendes N, Snelgrove D, Meenaghan E, Misra M et al. 2014 Fracture risk and areal bone mineral density in adolescent females with anorexia nervosa. International Journal of Eating Disorders [in press].

Fazeli PK, Bredella MA, Misra M, Meenaghan E, Rosen CJ, Clemmons DR, Breggia A, Miller KK \& Klibanski A $2010 a$ Preadipocyte factor-1 is associated with marrow adiposity and bone mineral density in women with anorexia nervosa. Journal of Clinical Endocrinology and Metabolism 95 407-413. (doi:10.1210/jc.2009-1152)

Fazeli PK, Lawson EA, Prabhakaran R, Miller KK, Donoho DA, Clemmons DR, Herzog DB, Misra M \& Klibanski A $2010 b$ Effects of recombinant human growth hormone in anorexia nervosa: a randomized, placebo-controlled study. Journal of Clinical Endocrinology and Metabolism 95 4889-4897. (doi:10.1210/jc.2010-0493)

Fazeli PK, Bredella MA, Freedman L, Thomas BJ, Breggia A, Meenaghan E, Rosen CJ \& Klibanski A 2012 Marrow fat and preadipocyte factor-1 levels decrease with recovery in women with anorexia nervosa. Journal of Bone and Mineral Research 27 1864-1871. (doi:10.1002/ jbmr.1640)

Fazeli PK, Wang IS, Miller KK, Herzog DB, Misra M, Lee H, Finkelstein JS, Bouxsein ML \& Klibanski A 2014 Teriparatide increases bone formation and bone mineral density in adult women with anorexia nervosa. Journal of Clinical Endocrinology and Metabolism [in press].

Golden NH, Lanzkowsky L, Schebendach J, Palestro CJ, Jacobson MS \& Shenker IR 2002 The effect of estrogen-progestin treatment on bone mineral density in anorexia nervosa. Journal of Pediatric and Adolescent Gynecology 15 135-143. (doi:10.1016/S1083-3188(02)00145-6)

Golden NH, Iglesias EA, Jacobson MS, Carey D, Meyer W, Schebendach J, Hertz S \& Shenker IR 2005 Alendronate for the treatment of osteopenia in anorexia nervosa: a randomized, double-blind, placebo-controlled trial. Journal of Clinical Endocrinology and Metabolism 90 3179-3185. (doi:10.1210/jc.2004-1659)

Gordon CM, Grace E, Emans SJ, Goodman E, Crawford MH \& Leboff MS 1999 Changes in bone turnover markers and menstrual function after short-term oral DHEA in young women with anorexia nervosa. Journal of Bone and Mineral Research 14 136-145. (doi:10.1359/jbmr. 1999.14.1.136)

Grinspoon S, Baum H, Lee K, Anderson E, Herzog D \& Klibanski A 1996 Effects of short-term recombinant human insulin-like growth factor I administration on bone turnover in osteopenic women with anorexia nervosa. Journal of Clinical Endocrinology and Metabolism 81 3864-3870.

Grinspoon S, Thomas E, Pitts S, Gross E, Mickley D, Miller K, Herzog D \& Klibanski A 2000 Prevalence and predictive factors for regional osteopenia in women with anorexia nervosa. Annals of Internal Medicine 133 790-794. (doi:10.7326/0003-4819-133-10-200011210-00011)

Grinspoon S, Thomas L, Miller K, Herzog D \& Klibanski A 2002 Effects of recombinant human IGF-I and oral contraceptive administration on bone density in anorexia nervosa. Journal of Clinical Endocrinology and Metabolism 87 2883-2891. (doi:10.1210/jcem.87.6.8574)

Hadigan CM, Anderson EJ, Miller KK, Hubbard JL, Herzog DB, Klibanski A \& Grinspoon SK 2000 Assessment of macronutrient and micronutrient intake in women with anorexia nervosa. International Journal of Eating Disorders 28 284-292. (doi:10.1002/1098-108X(200011)28:3\%3C;284:: AID-EAT5\%3E;3.0.CO;2-G)

Hamrick MW, Pennington C, Newton D, Xie D \& Isales C 2004 Leptin deficiency produces contrasting phenotypes in bones of the limb and spine. Bone 34 376-383. (doi:10.1016/j.bone.2003.11.020) 
Hamrick MW, Della-Fera MA, Choi YH, Pennington C, Hartzell D \& Baile CA 2005 Leptin treatment induces loss of bone marrow adipocytes and increases bone formation in leptin-deficient ob/ob mice. Journal of Bone and Mineral Research 20 994-1001. (doi:10.1359/JBMR.050103)

Hotta M, Shibasaki T, Sato K \& Demura H 1998 The importance of body weight history in the occurrence and recovery of osteoporosis in patients with anorexia nervosa: evaluation by dual X-ray absorptiometry and bone metabolic markers. European Journal of Endocrinology 139 276-283. (doi:10.1530/eje.0.1390276)

Housova J, Anderlova K, Krizova J, Haluzikova D, Kremen J, Kumstyrova T, Papezova H \& Haluzik M 2005 Serum adiponectin and resistin concentrations in patients with restrictive and binge/purge form of anorexia nervosa and bulimia nervosa. Journal of Clinical Endocrinology and Metabolism 90 1366-1370. (doi:10.1210/jc.2004-1364)

Jagielska G, Wolanczyk T, Komender J, Tomaszewicz-Libudzic C, Przedlacki J \& Ostrowski K 2002 Bone mineral density in adolescent girls with anorexia nervosa - a cross-sectional study. European Child \& Adolescent Psychiatry 11 57-62. (doi:10.1007/s007870200011)

Jurimae J, Jurimae T, Leppik A \& Kums T 2008 The influence of ghrelin, adiponectin, and leptin on bone mineral density in healthy postmenopausal women. Journal of Bone and Mineral Metabolism 26 618-623. (doi:10.1007/s00774-008-0861-5)

Kim SW, Her SJ, Park SJ, Kim D, Park KS, Lee HK, Han BH, Kim MS, Shin CS \& Kim SY 2005 Ghrelin stimulates proliferation and differentiation and inhibits apoptosis in osteoblastic MC3T3-E1 cells. Bone 37 359-369. (doi:10.1016/j.bone.2005.04.020)

Klibanski A, Biller B, Schoenfeld D, Herzog D \& Saxe V 1995 The effects of estrogen administration on trabecular bone loss in young women with anorexia nervosa. Journal of Clinical Endocrinology and Metabolism $\mathbf{8 0}$ 898-904.

Kojima M, Hosoda H, Date Y, Nakazato M, Matsuo H \& Kangawa K 1999 Ghrelin is a growth-hormone releasing acylated peptide from stomach. Nature 402 656-660. (doi:10.1038/45230)

Lawson EA, Donoho D, Miller KK, Misra M, Meenaghan E, Lydecker J, Wexler T, Herzog DB \& Klibanski A 2009 Hypercortisolemia is associated with severity of bone loss and depression in hypothalamic amenorrhea and anorexia nervosa. Journal of Clinical Endocrinology and Metabolism 94 4710-4716. (doi:10.1210/jc.2009-1046)

Lawson EA, Miller KK, Bredella MA, Phan C, Misra M, Meenaghan E, Rosenblum L, Donoho D, Gupta R \& Klibanski A 2010 Hormone predictors of abnormal bone microarchitecture in women with anorexia nervosa. Bone 46 458-463. (doi:10.1016/j.bone.2009.09.005)

Lawson EA, Eddy KT, Donoho D, Misra M, Miller KK, Meenaghan E, Lydecker J, Herzog D \& Klibanski A 2011a Appetite-regulating hormones cortisol and peptide YY are associated with disordered eating psychopathology, independent of body mass index. European Journal of Endocrinology 164 253-261. (doi:10.1530/EJE-10-0523)

Lawson EA, Donoho DA, Blum JI, Meenaghan EM, Misra M, Herzog DB, Sluss PM, Miller KK \& Klibanski A $2011 b$ Decreased nocturnal oxytocin levels in anorexia nervosa are associated with low bone mineral density and fat mass. Journal of Clinical Psychiatry 72 1546-1551. (doi:10.4088/ JCP.10m06617)

Lee P, Brychta RJ, Collins MT, Linderman J, Smith S, Herscovitch P, Millo C, Chen KY \& Celi FS 2013 Cold-activated brown adipose tissue is an independent predictor of higher bone mineral density in women. Osteoporosis International 24 1513-1518. (doi:10.1007/s00198-012-2110-y)

Lewiecki EM, Gordon CM, Baim S, Leonard MB, Bishop NJ, Bianchi ML, Kalkwarf HJ, Langman CB, Plotkin H, Rauch F et al. 2008 International Society for Clinical Densitometry 2007 Adult and Pediatric Official Positions. Bone 43 1115-1121. (doi:10.1016/j.bone.2008.08.106)

Lucas AR, Beard CM, O'Fallon WM \& Kurland LT 1991 50-year trends in the incidence of anorexia nervosa in Rochester, Minn.: a population-based study. American Journal of Psychiatry 148 917-922.

Lucas AR, Melton LJ III, Crowson CS \& O'Fallon WM 1999 Long-term fracture risk among women with anorexia nervosa: a population-based cohort study. Mayo Clinic Proceedings 74 972-977.
Mehler PS, Eckel RH \& Donahoo WT 1999 Leptin levels in restricting and purging anorectics. International Journal of Eating Disorders 26 189-194. (doi:10.1002/(SICI)1098-108X(199909)26:2\%3C;189::AIDEAT8\%3E;3.0.CO;2-V)

Miller KK, Lee EE, Lawson EA, Misra M, Minihan J, Grinspoon SK, Gleysteen S, Mickley D, Herzog D \& Klibanski A 2006 Determinants of skeletal loss and recovery in anorexia nervosa. Journal of Clinical Endocrinology and Metabolism 91 2931-2937. (doi:10.1210/jc.2005-2818)

Miller KK, Meenaghan E, Lawson EA, Misra M, Gleysteen S, Schoenfeld D, Herzog D \& Klibanski A 2011 Effects of risedronate and low-dose transdermal testosterone on bone mineral density in women with anorexia nervosa: a randomized, placebo-controlled study. Journal of Clinical Endocrinology and Metabolism 96 2081-2088. (doi:10.1210/ jc.2011-0380)

Milos G, Spindler A, Ruegsegger P, Seifert B, Muhlebach S, Uebelhart D \& Hauselmann HJ 2005 Cortical and trabecular bone density and structure in anorexia nervosa. Osteoporosis International 16 783-790. (doi:10.1007/s00198-004-1759-2)

Misra M, Miller K, Bjornson J, Hackman A, Aggarwal A, Chung J, Ott M, Herzog D, Johnson M \& Klibanski A 2003a Alterations in growth hormone secretory dynamics in adolescent girls with anorexia nervosa and effects on bone metabolism. Journal of Clinical Endocrinology and Metabolism 88 5615-5623. (doi:10.1210/jc.2003-030532)

Misra M, Soyka LA, Miller KK, Herzog DB, Grinspoon S, De Chen D, Neubauer G \& Klibanski A 2003b Serum osteoprotegerin in adolescent girls with anorexia nervosa. Journal of Clinical Endocrinology and Metabolism 88 3816-3822. (doi:10.1210/jc.2003-030088)

Misra M, Aggarwal A, Miller KK, Almazan C, Worley M, Soyka LA, Herzog DB \& Klibanski A 2004a Effects of anorexia nervosa on clinical, hematologic, biochemical, and bone density parameters in community-dwelling adolescent girls. Pediatrics 114 1574-1583. (doi:10.1542/peds.2004-0540)

Misra M, Miller KK, Almazan C, Ramaswamy K, Lapcharoensap W, Worley M, Neubauer G, Herzog DB \& Klibanski A 2004b Alterations in cortisol secretory dynamics in adolescent girls with anorexia nervosa and effects on bone metabolism. Journal of Clinical Endocrinology and Metabolism 89 4972-4980. (doi:10.1210/jc.2004-0723)

Misra M, Miller KK, Herzog DB, Ramaswamy K, Aggarwal A, Almazan C, Neubauer G, Breu J \& Klibanski A 2004c Growth hormone and ghrelin responses to an oral glucose load in adolescent girls with anorexia nervosa and controls. Journal of Clinical Endocrinology and Metabolism 89 1605-1612. (doi:10.1210/jc.2003-031861)

Misra M, Miller KK, Kuo K, Griffin K, Stewart V, Hunter E, Herzog DB \& Klibanski A $2005 a$ Secretory dynamics of leptin in adolescent girls with anorexia nervosa and healthy adolescents. American Journal of Physiology. Endocrinology and Metabolism 289 E373-E381. (doi:10.1152/ ajpendo.00041.2005)

Misra M, Miller KK, Kuo K, Griffin K, Stewart V, Hunter E, Herzog DB \& Klibanski A $2005 b$ Secretory dynamics of ghrelin in adolescent girls with anorexia nervosa and healthy adolescents. American Journal of Physiology. Endocrinology and Metabolism 289 E347-E356. (doi:10.1152/ ajpendo.00615.2004)

Misra M, Tsai P, Anderson EJ, Hubbard JL, Gallagher K, Soyka LA, Miller KK, Herzog DB \& Klibanski A $2006 a$ Nutrient intake in communitydwelling adolescent girls with anorexia nervosa and in healthy adolescents. American Journal of Clinical Nutrition 84 698-706.

Misra M, Miller KK, Tsai P, Gallagher K, Lin A, Lee N, Herzog DB \& Klibanski A $2006 b$ Elevated peptide YY levels in adolescent girls with anorexia nervosa. Journal of Clinical Endocrinology and Metabolism 91 1027-1033. (doi:10.1210/jc.2005-1878)

Misra M, Miller KK, Cord J, Prabhakaran R, Herzog DB, Goldstein M, Katzman DK \& Klibanski A 2007 Relationships between serum adipokines, insulin levels, and bone density in girls with anorexia nervosa. Journal of Clinical Endocrinology and Metabolism 92 2046-2052. (doi:10.1210/jc.2006-2855) 
Misra M, Prabhakaran R, Miller KK, Goldstein MA, Mickley D, Clauss L, Lockhart P, Cord J, Herzog DB, Katzman DK et al. 2008a Weight gain and restoration of menses as predictors of bone mineral density change in adolescent girls with anorexia nervosa-1. Journal of Clinical Endocrinology and Metabolism 93 1231-1237. (doi:10.1210/jc.2007-1434)

Misra M, Katzman DK, Cord J, Manning SJ, Mendes N, Herzog DB, Miller KK $\&$ Klibanski A $2008 b$ Bone metabolism in adolescent boys with anorexia nervosa. Journal of Clinical Endocrinology and Metabolism 93 3029-3036. (doi:10.1210/jc.2008-0170)

Misra M, McGrane J, Miller KK, Goldstein MA, Ebrahimi S, Weigel T \& Klibanski A 2009 Effects of rhIGF-1 administration on surrogate markers of bone turnover in adolescents with anorexia nervosa. Bone $\mathbf{4 5}$ 493-498. (doi:10.1016/j.bone.2009.06.002)

Misra M, Katzman D, Miller KK, Mendes N, Snelgrove D, Russell M, Goldstein MA, Ebrahimi S, Clauss L, Weigel T et al. 2011 Physiologic estrogen replacement increases bone density in adolescent girls with anorexia nervosa. Journal of Bone and Mineral Research 26 2430-2438. (doi:10.1002/jbmr.447)

Misra M, Katzman DK, Clarke H, Snelgrove D, Brigham K, Miller KK \& Klibanski A 2013 Hip structural analysis in adolescent boys with anorexia nervosa and controls. Journal of Clinical Endocrinology and Metabolism 98 2952-2958. (doi:10.1210/jc.2013-1457)

Modder UI, Clowes JA, Hoey K, Peterson JM, McCready L, Oursler MJ, Riggs BL \& Khosla S 2011 Regulation of circulating sclerostin levels by sex steroids in women and in men. Journal of Bone and Mineral Research 26 27-34. (doi:10.1002/jbmr.128)

Mora S, Pitukcheewanont P, Kaufman FR, Nelson JC \& Gilsanz V 1999 Biochemical markers of bone turnover and the volume and the density of bone in children at different stages of sexual development. Journal of Bone and Mineral Research 14 1664-1671. (doi:10.1359/jbmr.1999.14.10.1664)

Ponrartana S, Aggabao PC, Hu HH, Aldrovandi GM, Wren TA \& Gilsanz V 2012 Brown adipose tissue and its relationship to bone structure in pediatric patients. Journal of Clinical Endocrinology and Metabolism 97 2693-2698. (doi:10.1210/jc.2012-1589)

Riggs B 2000 The mechanisms of estrogen regulation of bone resorption. Journal of Clinical Investigation 106 1203-1204. (doi:10.1172/JCI11468)

Riggs BL, Khosla S \& Melton LJ III 2002 Sex steroids and the construction and conservation of the adult skeleton. Endocrine Reviews 23 279-302. (doi:10.1210/edrv.23.3.0465)

Scacchi M, Pincelli A, Caumo A, Tomasi P, Delitala G, Baldi G \& Cavagnini F 1997 Spontaneous nocturnal growth hormone secretion in anorexia nervosa. Journal of Clinical Endocrinology and Metabolism 82 3225-3229. (doi:10.1210/jcem.82.10.4275)

Schellinger D, Lin CS, Hatipoglu HG \& Fertikh D 2001 Potential value of vertebral proton MR spectroscopy in determining bone weakness. AJNR. American Journal of Neuroradiology 22 1620-1627.

Schousboe JT, Shepherd JA, Bilezikian JP \& Baim S 2013 Executive summary of the 2013 International Society for Clinical Densitometry Position Development Conference on bone densitometry. Journal of Clinical Densitometry 16 455-466. (doi:10.1016/j.jocd.2013.08.004)

Sienkiewicz E, Magkos F, Aronis KN, Brinkoetter M, Chamberland JP, Chou S, Arampatzi KM, Gao C, Koniaris A \& Mantzoros CS 2011 Long-term metreleptin treatment increases bone mineral density and content at the lumbar spine of lean hypoleptinemic women. Metabolism: Clinical and Experimental 60 1211-1221. (doi:10.1016/j.metabol.2011.05.016)
Smink FR, van Hoeken D \& Hoek HW 2013 Epidemiology, course, and outcome of eating disorders. Current Opinion in Psychiatry 26 543-548. (doi:10.1097/YCO.0b013e328365a24f)

Soyka LA, Misra M, Frenchman A, Miller KK, Grinspoon S, Schoenfeld DA \& Klibanski A 2002 Abnormal bone mineral accrual in adolescent girls with anorexia nervosa. Journal of Clinical Endocrinology and Metabolism 87 4177-4185. (doi:10.1210/jc.2001-011889)

Stoving RK, Veldhuis JD, Flyvbjerg A, Vinten J, Hangaard J, Koldkjaer OG, Kristiansen J \& Hagen C 1999 Jointly amplified basal and pulsatile growth hormone $(\mathrm{GH})$ secretion and increased process irregularity in women with anorexia nervosa: indirect evidence for disruption of feedback regulation within the GH-insulin-like growth factor I axis. Journal of Clinical Endocrinology and Metabolism 84 2056-2063.

Strokosch GR, Friedman AJ, Wu SC \& Kamin M 2006 Effects of an oral contraceptive (norgestimate/ethinyl estradiol) on bone mineral density in adolescent females with anorexia nervosa: a double-blind, placebocontrolled study. Journal of Adolescent Health 39 819-827. (doi:10.1016/ j.jadohealth.2006.09.010)

Tagami T, Satoh N, Usui T, Yamada K, Shimatsu A \& Kuzuya H 2004 Adiponectin in anorexia nervosa and bulimia nervosa. Journal of Clinical Endocrinology and Metabolism 89 1833-1837. (doi:10.1210/ jc.2003-031260)

Tamma R, Colaianni G, Zhu LL, DiBenedetto A, Greco G, Montemurro G, Patano N, Strippoli M, Vergari R, Mancini L et al. 2009 Oxytocin is an anabolic bone hormone. PNAS 106 7149-7154. (doi:10.1073/pnas. 0901890106)

Theintz G, Buchs B, Rizzoli R, Slosman D, Clavien H, Sizonenko P \& Bonjour J 1992 Longitudinal monitoring of bone mass accumulation in healthy adolescents: evidence for a marked reduction after 16 years of age at the levels of lumbar spine and femoral neck in female subjects. Journal of Clinical Endocrinology and Metabolism 75 1060-1065.

Utz AL, Lawson EA, Misra M, Mickley D, Gleysteen S, Herzog DB, Klibanski A \& Miller KK 2008 Peptide YY (PYY) levels and bone mineral density (BMD) in women with anorexia nervosa. Bone 43 135-139. (doi:10.1016/j.bone. 2008.03.007)

Wang Y \& Sul HS 2009 Pref-1 regulates mesenchymal cell commitment and differentiation through Sox9. Cell Metabolism 9 287-302. (doi:10.1016/ j.cmet.2009.01.013)

Welt CK, Chan JL, Bullen J, Murphy R, Smith P, DePaoli AM, Karalis A \& Mantzoros CS 2004 Recombinant human leptin in women with hypothalamic amenorrhea. New England Journal of Medicine $\mathbf{3 5 1}$ 987-997. (doi:10.1056/NEJMoa040388)

Wojcik MH, Meenaghan E, Lawson EA, Misra M, Klibanski A \& Miller KK 2010 Reduced amylin levels are associated with low bone mineral density in women with anorexia nervosa. Bone 46 796-800. (doi:10.1016/j.bone.2009.11.014)

Wong IP, Driessler F, Khor EC, Shi YC, Hormer B, Nguyen AD, Enriquez RF, Eisman JA, Sainsbury A, Herzog H et al. 2012 Peptide YY regulates bone remodeling in mice: a link between gut and skeletal biology. PLOS ONE 7 e40038. (doi:10.1371/journal.pone.0040038)

Zipfel S, Seibel MJ, Lowe B, Beumont PJ, Kasperk C \& Herzog W 2001 Osteoporosis in eating disorders: a follow-up study of patients with anorexia and bulimia nervosa. Journal of Clinical Endocrinology and Metabolism 86 5227-5233. (doi:10.1210/jcem.86.11.8050)

Received in final form 18 February 2014

Accepted 28 February 2014 http://joe.endocrinology-journals.org DOI: 10.1530/JOE-14-0039
() 2014 Society for Endocrinology Printed in Great Britain 